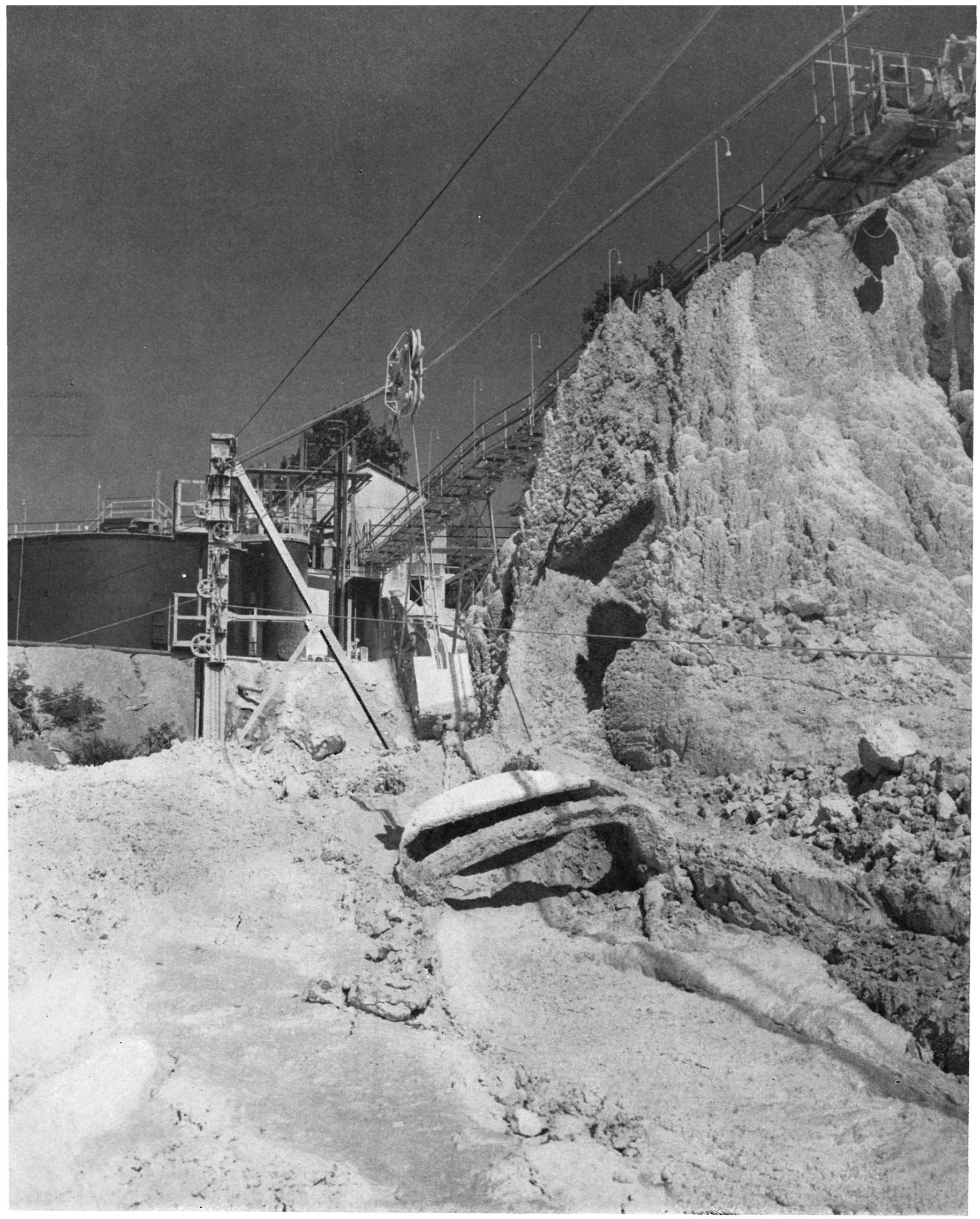

811.6

\title{
traíllas de arrastre Sauerman
}




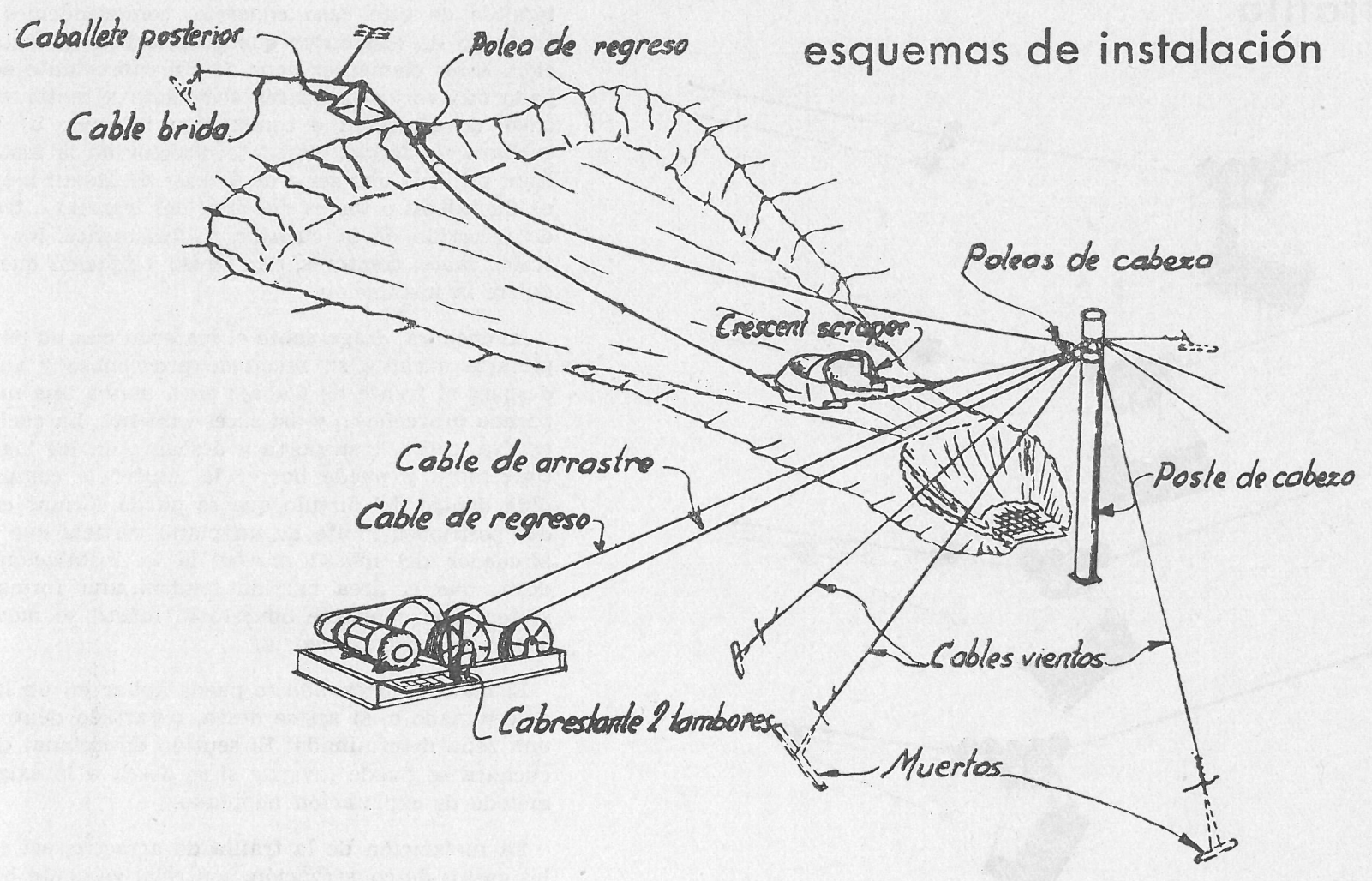

La creciente mecanización en obra y taller ha dado paso a un poderoso elemento auxiliar, que se hace insustituíble en las explotaciones de graveras $y$, en general, en toda clase de acopios de materiales áridos en la construcción, y en los grandes movimientos de materiales y minerales que han de apilarse o depositar sobre tolvas de cargaderos. Este auxiliar es la traílla de arrastre.

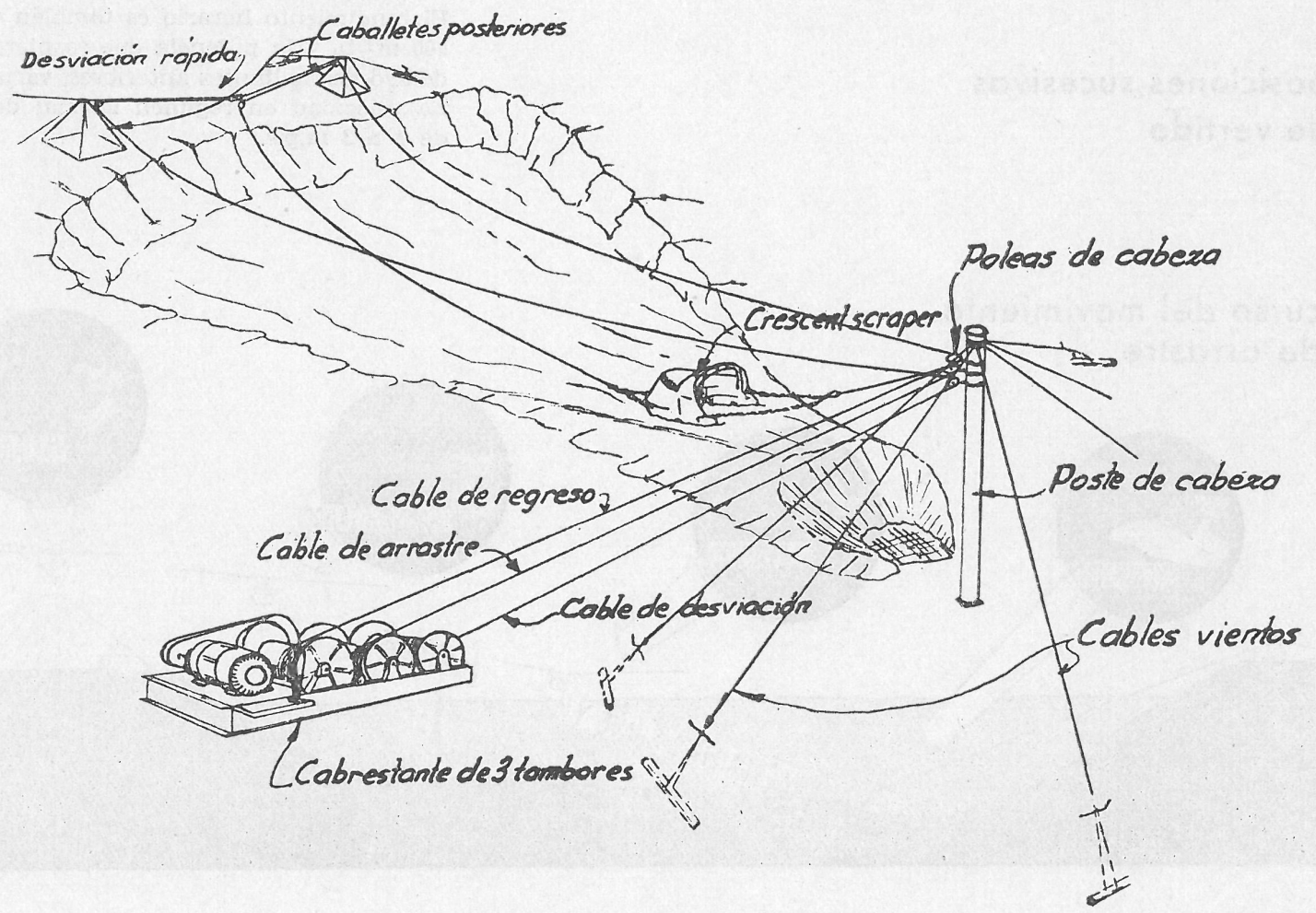




\section{trailla}

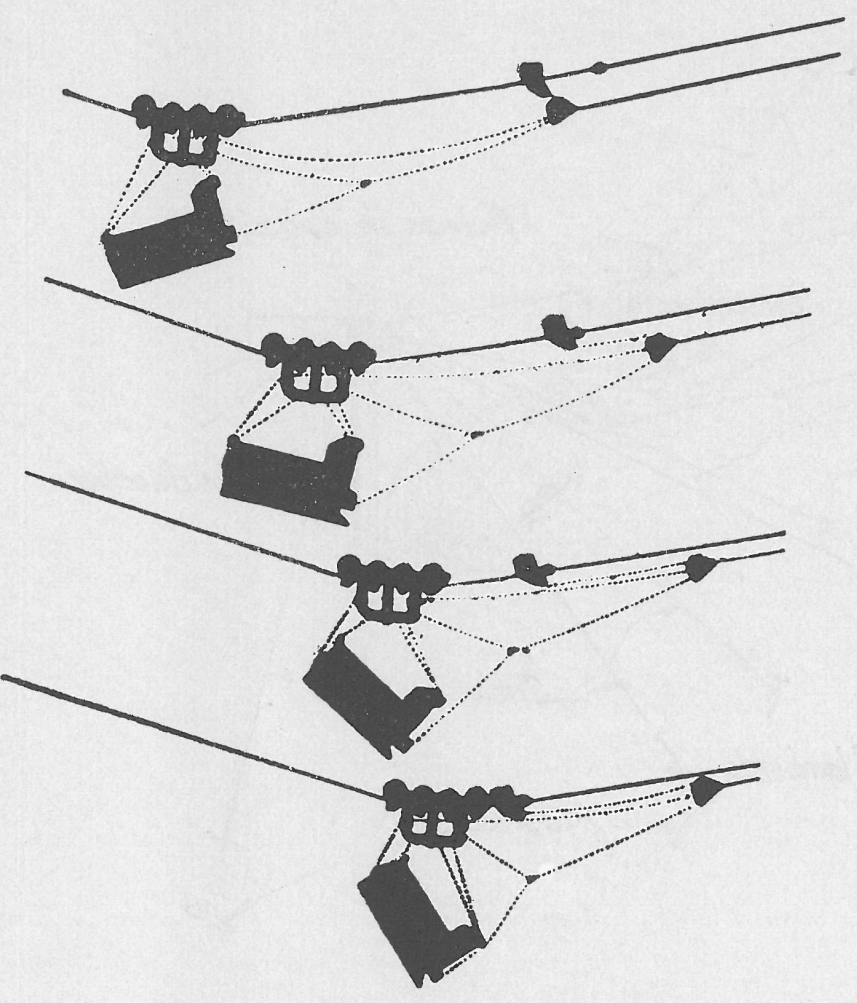

\author{
posiciones sucesivas \\ de vertido
}

Bajo la denominación de traílla de arrastre, y tratándose de este caso concreto, comprendemos un conjunto de elementos que constituyen la instalación. Estos elementos son: a) Un cabrestante equipado con varios tambores accionado a motor eléctrico, de explosión o combustión interna; b) Una cuchara sin fondo, elemento director de la instalación; c) Toda una serie de poleas; d) Mástil mayor; e) Castilletes o torres del final del trazado o tramo de recorrido de la cuchara $y$, finalmente, los distintos cables tractores, de regreso y fijación que requiere la instalación.

La cuchara, draga sobre el material que ha de explotarse durante su recorrido provechoso y vuelve después al frente de trabajo para seguir una nueva pasada provechosa, y así sucesivamente. La cuchara excava, carga, transporta y descarga en los lugares convenidos y puede barrer la superficie comprendida dentro del ángulo que se puede formar entre dos posiciones límite de un plano vertical que gire alrededor del mástil mayor de la instalación, es decir, que el área barrida tendría una forma de sector si el caballete opuesto al mástil se moviese según una circunferencia.

El material excavado se puede apilar en un lugar determinado o, si así se desea, repartirlo dentro de una zona determinada. El sentido direccional de la cuchara se puede invertir si se desea o lo exige el método de explotación adoptado.

La instalación de la traílla de arrastre, así como los gastos de conservación, son relativamente bajos. El consumo de energía es del orden de $3 / 4 \mathrm{kWh}$ por tonelada de material arrastrado en una longitud de 100 metros.

Una de las particularidades de la traílla Sauerman consiste en no requerir, en términos generales, más que un conductor, el cual no necesita, precisamente, ser un especialista.

La capacidad de la cuchara varía de 0,2 a $12 \mathrm{~m}^{8}$. El rendimiento horario es también variable, de 6 a $500 \mathrm{~m}^{3} / \mathrm{h}$, y la potencia que requiere la instalación, dentro de los límites anteriores, varía de 5 a $600 \mathrm{CV}$. La velocidad en régimen normal de la cuchara es de 1 a 3 m.p.s.

\section{curso del movimiento de arrastre}

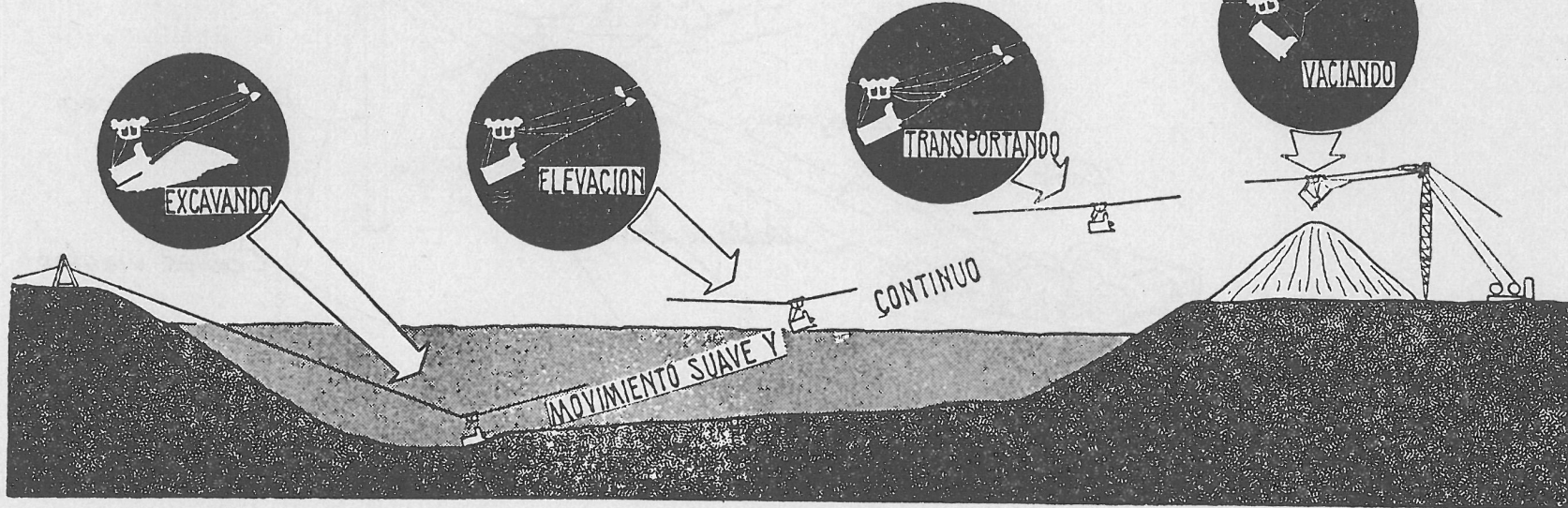


Dragado del Guadalquivir en Córdoba.

Descarga de grava sobre tovera.

La traílla al salir del río.

Dragado del fondo del mar en Almería.

Limpieza de un embalse.

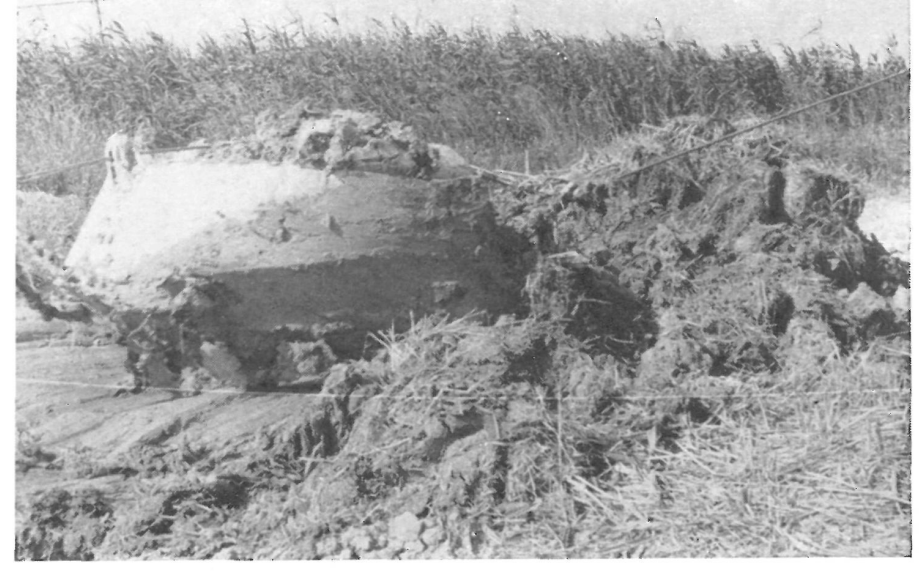

Para el estudio de un proyecto de instalación de una traílla de arrastre se requiere, aparte de la presencia de un especialista en esta materia, el conocimiento topográfico del lugar, potencia de la capacidad que ha de explotarse y rendimiento horario que se proyecta. $\mathrm{Y}$, naturalmente, la composicion granulométrica de los materiales que se han de extraer, su densidad y adherencia son datos necesarios que complementan el estudio del proyecto.

La conocida casa Sauerman Bros, de Bellwood (Illinois), especializada en este tipo de maquinaria auxiliar, además de fabricar esta maquinaria, son expertos conocedores de las múltiples aplicaciones que presentan, y han permitido, bajo licencia, la fabricación de estas máquinas en España, para lo cual prestan su ayuda técnica.

El elemento principal de una instalación de esta naturaleza es la cuchara, minuciosamente estudiada por la casa constructora que, después de múltiples experiencias, ha llegado a la conclusión de que su forma es de gran influencia en el rendimiento, mientras que el peso propio no tiene la importancia que en principio se le concedió. Con la cuchara actual, tanto el peso como la fuerza de tracción necesaria para arrastrarla se han reducido en un $50 \%$.

La conservación de los cables se ha mejorado notablemente, pues al no ser arrastrados sobre el terreno, manteniéndolos en posición apropiada por medio de ajustes en el mástil mayor y caballetes de apoyo, no existe rozamiento. Los tambores, poleas y enrollamientos del cable en los mismos han sido cuidadosamente estudiados con objeto de alargar la vida de los cables disminuyendo la intensa y continua fatiga de los cambios de dirección de los mismos.
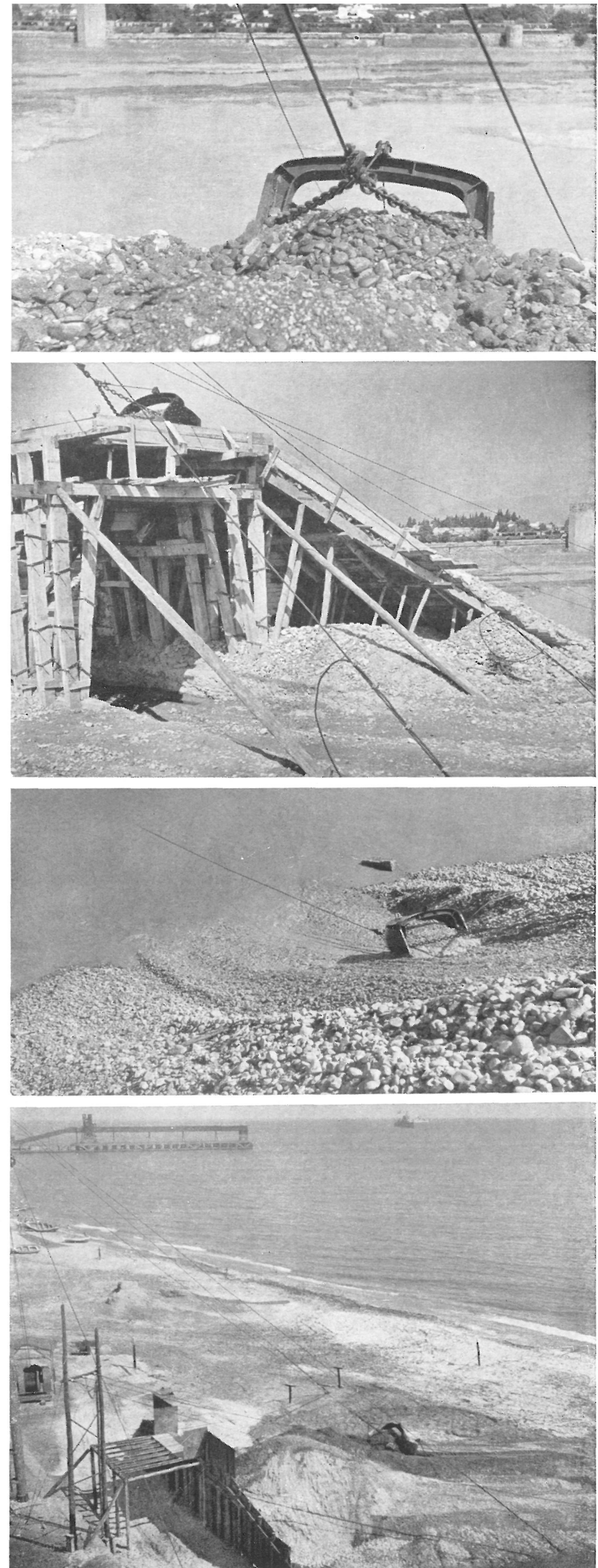
Dispositivo para la carga de vagones.

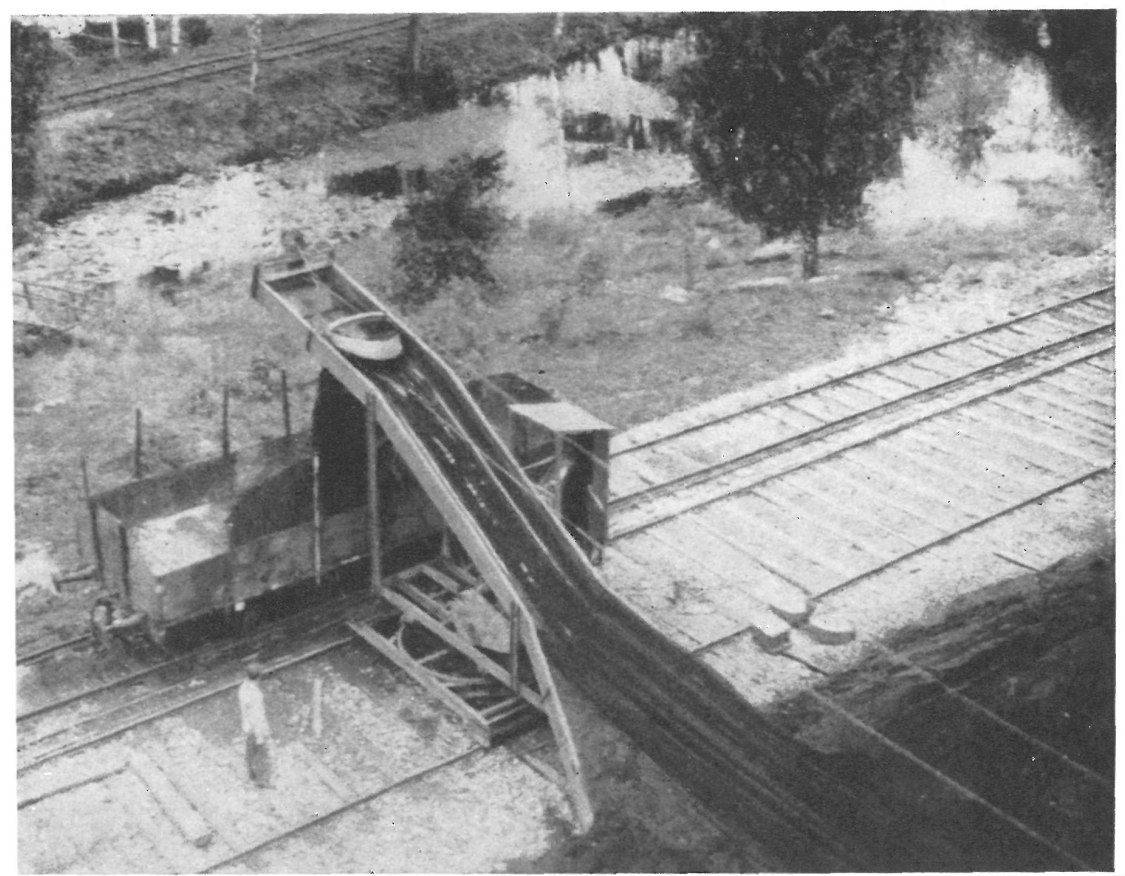

Torre móvil para la carga de carbón.

Dispositivo de carga en la instalación de Torrevieja.

Torre móvil en las instalaciones de Torrevieja.

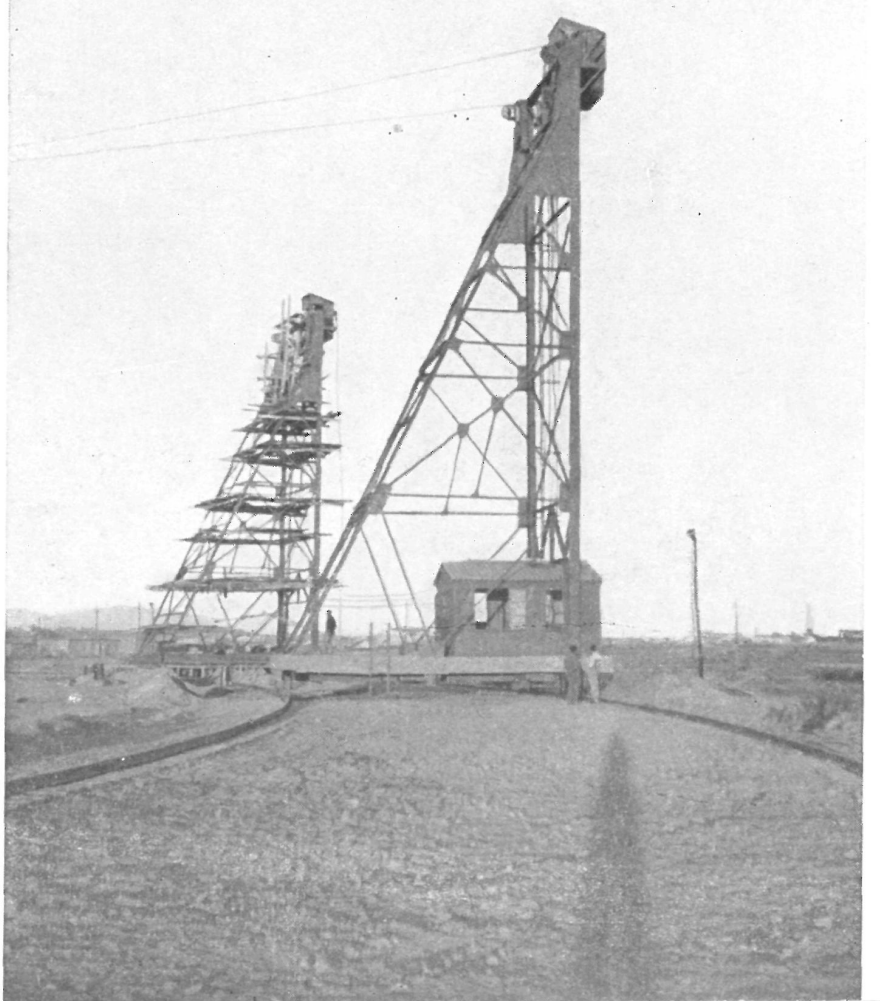

Para evitar que el cable caiga sobre el terreno al dejar loco el tambor en el regreso de la cuchara al cambiar de dirección, se ha sincronizado un freno con los cambios de giro del tambor, que mantiene el cable continuamente lotando en el aire.

\section{Instalaciones en España}

Entre las múltiples aplicaciones de este tipo de instalaciones citaremos, como las más importantes de la ingeniería civil, la excavación y transporte de arcillas para las tejeras, movimiento de tierras y excavaciones, nivelaciones de tierras y excavaciones, nivelaciones
de terrenos, apilamiento en canteras, de terrenos, apilamiento en canteras, construcción de diques para presas, encauzamientos, dragados marítimos y des dimensiones en canteras, etc., etc.

Actualmente, se hallan en servicio en España unas 150 instalaciones de la casa Sauerman, cuyas capacidades de cuchara varían de 400 a 3.000 litros. Fn estas instalaciones se han montado mandos electroneumáticos t $y$ torres cuya altura varia de 4 ría de 4 a 24 metros.
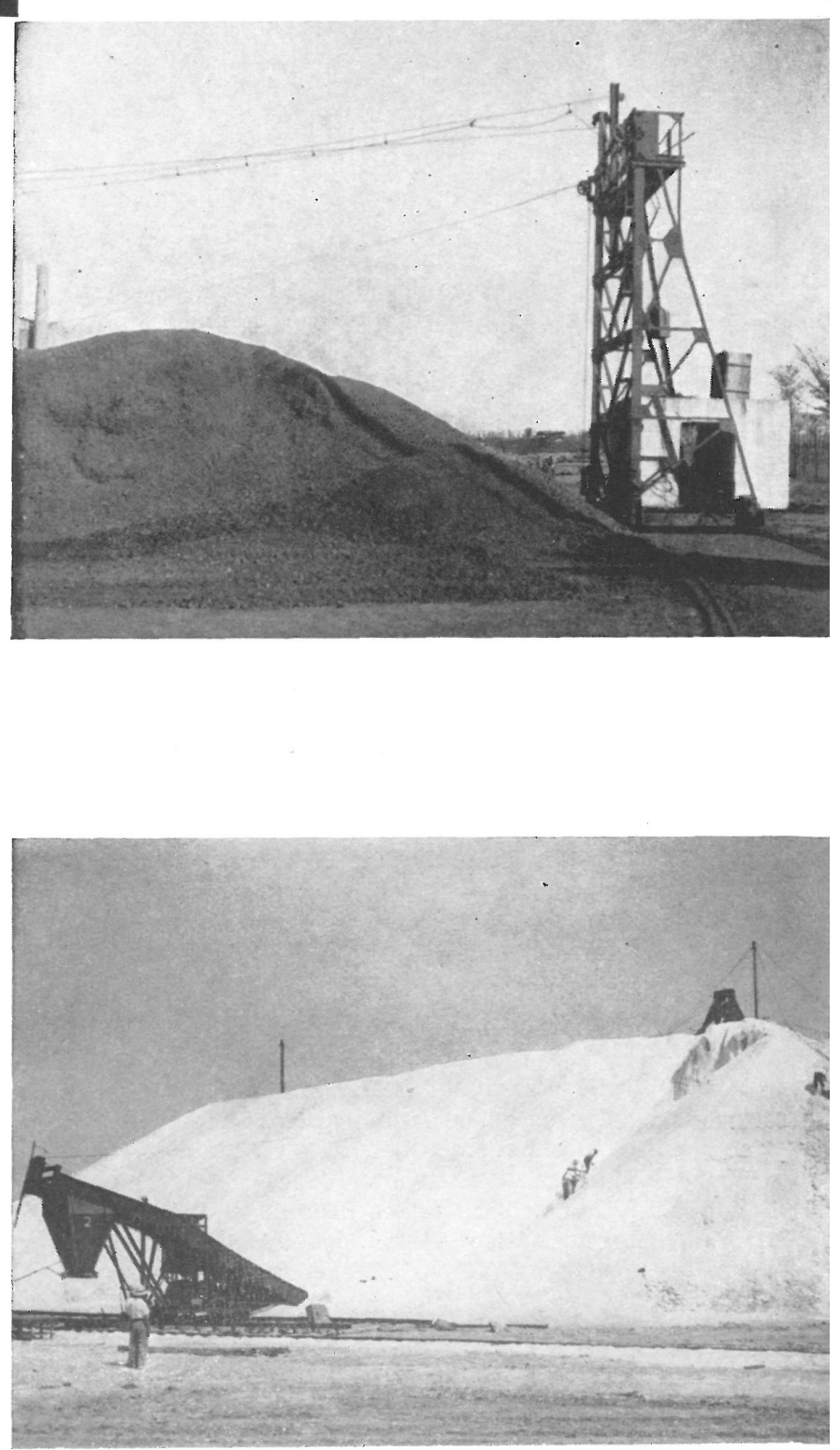